\title{
Arbor
}

\section{El Hispanismo actual en los países de habla alemana}

\section{Frank Baasner}

Arbor CLXVIII, 664 (Abril 2001), 551-562 pp.

El concepto mismo de «hispanismo», visto desde la realidad del mundo académico en los países de habla alemana ${ }^{1}$, es tan ancho y multiforme que pide una mejor definición antes de esbozar un panorama de las tendencias actuales. Tradicionalmente, se entienden por hispanismo las áreas de investigación vinculadas a la lengua y literatura españolas (de lengua castellana). En este sentido «hispanismo» sería un equivalente de «Hispanistik» en alemán. Sin embargo, el enorme crecimiento del interés por el mundo hispanohablante (peninsular y americano) permitió el desarrollo de competencias muy especializadas también en otras disciplinas universitarias, tales como la historia (contemporánea), la sociología, las ciencias políticas, la comunicación intercultural, la historia del arte, etc. Al mismo tiempo, la tradicional «Hispanistik» se abrió, por lo menos en algunas universidades, a nuevos temas de investigación, tales como el cine, los mass-media en general, conceptos de identidad cultural, etc. Estas tendencias de apertura, que coinciden con la búsqueda de investigaciones interdisciplinarias, se discuten en Alemania bajo el concepto de «Kulturwissenschaft» (ciencias de la civilización y de la cultura), concepto camaleónico quizá, pero útil para lanzar un debate amplio sobre el futuro de las tradicionales humanidades.

En el artículo panorámico siguiente, utilizo «hispanismo» sobre todo sensu strictu (o sea como equivalente de "Hispanistik»), pero sí haré hincapié en algunos puntos fuertes del hispanismo sensu latu. Me limitaré a tendencias actuales, ya que el hispanismo alemán fue objeto de otros artículos panorámicos precedentes ${ }^{2}$. Quisiera subrayar que, por supuesto, tal panorama no puede ser completo sino que tiene ante todo que presentar nuevas tendencias que quizá indican un desarrollo futuro. Para los lectores que necesiten más información so- 
bre las publicaciones, los departamentos y más datos estadísticos de las universidades de lengua alemana, son muy útiles las publicaciones recientes indicadas en la nota ${ }^{3}$. Anticipando algunas observaciones que desarrollaré más detalladamente al final del artículo quisiera mencionar el interés grandísimo, creciente ininterrumpidamente desde hace años, para el idioma castellano y para las culturas hispanohablantes; sin embargo mencionaré también el hecho de que las estructuras tradicionales, sea a nivel de liceo, sea a nivel de las facultades, quizá tendrán que evolucionar para dar cabida adecuada al auge del hispanismo.

\section{Aspectos administrativos}

Tradicionalmente la hispanística forma parte de la disciplina de «romanística» (lenguas y literaturas de todos los países de habla románica $)^{4}$. Sin embargo, desde hace por lo menos 25 años, la hispanística desarrolló su independencia como disciplina universitaria. Podríamos tomar la creación de una Asociación de Hispanistas Alemanes en 1975 como símbolo de la separación entre hispanismo y romanística ${ }^{5}$. Este proceso de separación de las diferentes áreas de investigación se hizo más evidente (para todos los idiomas románicos) en los últimos años, no sin discusiones polémicas alrededor de la supuesta pérdida de una gran tradición académica basada en las generaciones de la época romántica. Hay quien sostiene que la separación de la romanística en áreas monolingües y mono-culturales significa abandonar una visión necesariamente comparatista de cada una de las literaturas (y lenguas); por otro lado se pone énfasis en el hecho de que el mundo académico se está especializando cada vez más y que la situación alemana es anacrónica. Ambas posiciones tienen fuertes argumentos, y el resultado más positivo de dichas polémicas es, a mi modo de ver, una mayor diversificación entre las diferentes universidades. Según las posibilidades (muchas veces muy limitadas debido a la escasez de personal docente) hay mayor o menor especialización en una literatura (o lengua) o en la perspectiva multi-cultural o sea comparatista.

En Austria, la situación es básicamente la misma. Debido a una reciente reforma de la organización de las universidades se están creando estructuras orientadas más bien hacia grupos o incluso centros de investigación, una especie de «sub-departamentos» para disminuir el aislamiento individualista de los proyectos de investigación. 
El Hispanismo actual en los países de habla alemana

El hispanismo suizo vive una situación difícil debido al hecho de que el francés y el italiano son idiomas hablados en Suiza, de forma que el español es el idioma románico «extranjero» respecto a los mencionados. Sin embargo, la internacionalización de las universidades suizas es mayor (en el campo de la romanística) que en Alemania o Austria: un gran número de los catedráticos, sea de francés, de italiano o de castellano, proceden de Francia, Italia o España, algo casi impensable en Alemania o Austria.

El movimiento hacia la especialización se refleja no solamente en la división de la romanística tradicional en diferentes ramos tales como el francés, el castellano y el italiano, sino que también se expresa en una mayor especialización dentro del área de los estudios sobre la península ibérica: Mientras hace años el catalán o el gallego fueron como «apéndices» dentro del hispanismo, tenemos hoy, por lo menos en algunas universidades, una catalanística independiente (hay una asociación de catalanistas, hay publicaciones periódicas especializadas). ${ }^{6} \mathrm{El}$ gallego también se hizo «independiente»: en Tréveris por ejemplo hay un centro de estudios gallegos. Ni el catalán ni el gallego serán objeto de nuestra visión panorámica del hispanismo en los países de habla alemana.

Las literaturas hispanohablantes de América gozan de un inmenso interés tanto en la investigación como por parte de los estudiantes. Este interés, que crece desde hace más o menos veinte años, se traduce en un sinnúmero de proyectos, publicaciones (revistas como la Iberoamericana de Hamburgo o series de publicaciones como la del Erlangen/Nürnberg, los Lateinamerika-Studien) e incluso estructuras a nivel de bibliotecas especializadas. ${ }^{7}$

Es un placer para mí añadir que los dos Institutos Cervantes, el de Bremen y el de Munich, contribuyen al desarrollo y al florecimiento de las actividades hispanistas en Alemania; el de Viena lo hace en Austria y el de Berna en Suiza.

\section{Proyectos subvencionados y congresos nacionales}

Antes de recorrer diferentes áreas de investigación quisiera dar algunas informaciones sobre los proyectos de investigación subvencionados por las instituciones estatales (que tienen un papel semejante al del Consejo Superior de Investigaciones Científicas). Efectivamente, debido a la escasez de personal es difícil llevar a cabo investigaciones de cierta envergadura sin la ayuda de la Deutsche Forschungsge- 
meinschaft (DFG, Alemania, «www.dfg.de»), el Fonds zur Förderung der wissenschaftlichen Forschung (FWF, Austria, «www.fwf.ac.at») o el Schweizerischer Nationalfonds (SNF, Suiza, «www.snf.ch»). También hay fundaciones privadas muy activas en la promoción de la investigación, tal como la VW-Stiftung, la Robert-Bosch-Stiftung u otros más, pero las instituciones estatales son las que tienen más peso y representatividad.

Cabe subrayar en seguida que no hay muchos proyectos (exclusivamente) hispanísticos subvencionados ${ }^{8}$. En el sector lingüístico, aparte los proyectos de historia de la hispanística (o romanística ${ }^{9}$ ), hay un solo proyecto con referencia al español peninsular, mientras dos se refieren al español de América. En el sector literario, también hay uno solo, sobre la novela picaresca. El año pasado empezó otro sobre la crítica literaria del siglo XIX. Esta sorprendente situación se refleja igualmente en la lista de los «Graduiertenkollegs» (Escuelas de postgraduados y postdoctorados): ni uno de tema exclusivamente hispánico, algunos sin embargo con la participación de romanistas ${ }^{10}$. Eso no significa, por supuesto, que no haya investigación en casi la totalidad de universidades alemanas (eso lo veremos más adelante), pero sí demuestra que la hispanística como disciplina carece de verdaderos centros de investigación, que la vinculación a la romanística tradicional tiene - entre muchos aspectos positivos-desventajas evidentes.

Hay un número sorprendente de proyectos romanísticos (entre los subvencionados por la DFG) que se refieren a diccionarios, colecciones de datos, bibliografías históricas, manuales, etc., proyectos sin duda útiles, pero que al mismo tiempo reflejan quizá una fase de saber «cumulativo» en el desarrollo de la disciplina.

Una mirada comparativa a Austria acentúa aún más la situación poco satisfactoria en Alemania. El Fonds zur Förderung der wissenschaftlichen Forschung (FWF) financia total o parcialmente proyectos hispanísticos sobre poesía contemporánea, los españoles en Austria en el siglo XVI, la Edad Media en la crítica literaria del siglo XIX, y, en el campo lingüístico, uno sobre las interdependencias entre diccionarios castellanos y portugueses.

En Suiza el Schweizerischer Nationalfonds (SNF) subvenciona un solo proyecto hispanista, cuyo tema son las kharjas. En comparación con los proyectos sobre temas franceses e italianos el hispanismo casi no existe a nivel del SNF; situación debida al hecho mencionado arriba, es decir el carácter oficial del francés e italiano como lenguas habladas en Suiza.

Como la mayor parte de la investigación depende de individuos y de las iniciativas singulares de universidades, la organización de congresos también es el resultado de intereses particulares. Sin embargo, como he- 
El Hispanismo actual en los países de habla alemana

mos visto, en el campo de proyectos de investigación las subvenciones oficiales permiten destacar algunas líneas generales características. De manera análoga merece la pena mirar el programa de los congresos nacionales de la Asociación de Hispanistas Alemanes para comprender los rasgos fundamentales de los últimos años. Cada dos años los miembros del Deutscher Hispanistenverband proponen temas para las diferentes secciones del congreso, así que se puede presumir cierta representatividad de los temas. El último congreso nacional (1999), pues, muestra muy claramente que las tendencias actuales más destacadas se refieren a la literatura española contemporánea ( 5 de las 11 secciones) y al mundo americano (2 secciones). La tendencia de dar gran peso a las culturas hispanoamericanas se acentúa aún más en las preparaciones del próximo congreso, que se celebrará el año 2001 en Leipzig.

\section{Tendencias en la investigación}

Una primera constatación global se refiere a una tendencia ya mencionada: la creciente importancia del estudio de las literaturas y culturas de Hispanoamérica. Efectivamente, desde los temas predominantes en la enseñanza hasta los temas escogidos para el doctorado, hay una tendencia innegable hacia el «nuevo mundo». Dentro de poco llegará el momento en que la constitución como disciplina independiente será una evidencia: la situación actual que establece una especie de concurrencia entre el español peninsular y el español de América parece poco satisfactoria. Habrá (ya las hay), sin duda, algunas universidades especializadas más bien en uno u otro campo de investigación. Dejaré de lado aquí los estudios sobre Hispanoamérica ${ }^{11}$. Las siguientes observaciones sobre algunos aspectos interesantes en la investigación darán forzosamente, repito, una visión parcial de la realidad en las universidades de lengua alemana. Para asegurar un mínimo de representatividad y objetividad sin acumular fichas bibliográficas me basaré en los datos publicados por las mismas universidades: en el libro sobre la Hispanistik an den Hochschulen in Deutschland, Österreich und der deutschsprachigen Schweiz los 60 departamentos interrogados mencionan, más o menos detalladamente, sus campos de investigación más importantes. A partir de estos datos he intentado establecer una estadística que permite destacar los rasgos más evidentes en los intereses actuales de investigación hispanista.

En el campo de la lingüística podemos distinguir dos sectores: las investigaciones diacrónicas (25\%) y las sincrónicas. En el campo de la sin- 
cronía un poco más de la mitad (o sea casi $40 \%$ del total) son temas de la sociolingüística, lo demás son temas de gramática, lexicografía, etc. (30\%). Tres veces se mencionan temas de didáctica. En la parte diacrónica, cuentan proyectos prestigiosos muy conocidos como el Diccionario del Español Medieval (Heidelberg). En la parte sincrónica, hay últimamente una tendencia innegable hacia investigaciones que se pueden denominar de sociolingüística (p.ej. el proyecto de la Universidad de Bochum sobre el español en Internet). Hay que añadir que en el sector de la lingüística sigue la fuerte tradición de la romanística «comparativa» ${ }^{12}$, sin duda en mayor medida que en el campo de la literatura. Por eso muchas investigaciones se refieren a dos o más idiomas, así que una estadística exclusivamente de temas hispánicos será forzosamente parcial.

En el campo de la literatura he clasificado por épocas: Edad Media, Siglos de Oro, siglo XVIII, siglo XIX, siglo XX (dividiendo este último en dos fases, hasta 1975 y después). La primera constatación, y la más evidente, es que dos épocas acumulan tres cuartos de los intereses de investigación mencionados: el Siglo de Oro y el siglo XX. Pero procedamos con orden. La Edad Media (6\%) parece no gozar de mucho prestigio, un hecho sorprendente si se piensa en el origen (por lo menos parcialmente romántico) de la romanística y en los importantes trabajos empezados durante los años 70 en una perspectiva moderna de sociología de la literatura (cito como ejemplo el Grundri $\beta$ der romanischen Literaturen des Mittelalters, visión panorámica amplia de la cultura literaria medieval en su conjunto). Hoy en día, hay pocas universidades donde se investigue la Edad Media española desde una perspectiva literaria o lingüística. La Edad de Oro, en cambio, sigue desempeñando un papel importantísimo, como lo tuvo desde los comienzos de la hispanística moderna de lengua alemana en el siglo XIX. En un artículo reciente ${ }^{13}$ Wido Hempel retrata minuciosamente los trabajos publicados en los últimos veinte años, de manera que aquí me puedo limitar a las tendencias generales. Hempel destaca un interés decreciente por el teatro del Siglo de Oro, lo que sin duda corresponde a la realidad. A pesar del menor interés que el Siglo de Oro (ante todo el teatro) parece suscitar entre los jóvenes investigadores, el porcentaje entre los campos de investigación mencionados por los departamentos es del 35\%. Es difícil hacer un análisis más detallado de lo que se esconde bajo el concepto de «Siglo de Oro» ya que en la mayoría de los casos se habla simplemente de Siglo de Oro como campo de interés sin matizar. Si hay autores que aparecen más a menudo, se trata de Calderón (lo que no puede sorprender considerando la tradición decimonónica) y de Cervantes.

La situación es totalmente diferente con respecto al siglo XVIII. Mientras que en los años 70 y 80 hubo un verdadero florecimiento de estudios 


\section{El Hispanismo actual en los países de habla alemana}

sobre el siglo ilustrado ${ }^{14}$, el interés parece haberse desplazado hacia otros sectores de la literatura hispánica. Sólo el 7\% de las menciones se refiere al siglo XVIII, mientras que en España en los años 90 vieron la luz numerosas publicaciones sobre el XVIII, sean ediciones de autores dieciochescos, sean estudios sobre aspectos de la vida literaria española de aquella época. Aún más sorprendente es la escasez de estudios sobre el siglo XIX. Con un $8 \%$ de referencias la época romántica y la del realismo tienen pocos adeptos. ${ }^{15} \mathrm{El}$ realismo y naturalismo están incluso más presentes que el romanticismo. En Austria hay un proyecto sobre el romanticismo en Salzburg, y en la universidad de Zürich se trabaja regularmente sobre temas decimonónicos. Esta falta de estudios sobre el siglo XIX sorprende sobretodo porque en otros países se puede observar desde hace por lo menos diez años una actividad multiforme, riquísima en las investigaciones sobre el siglo XIX, primordialmente su primera mitad. Quizá habrá que esperar algunos años más antes que esta nueva visión, que a mi modo de ver está vinculada con la búsqueda de las posibles raíces de la España moderna, llegue a las aulas alemanas, austríacas y suizas.

El siglo XX, en cambio, está omnipresente en casi la totalidad de los departamentos. Desde las vanguardias hasta los años 90 la literatura española ocupa a los investigadores de todas las generaciones. Como ya he dicho, la época posterior al franquismo goza de interés particular, y no es una exageración cuando se dice que gran parte de la buena coyuntura actual del hispanismo (alemán) es debida al hecho de que la España postfranquista suscitó un verdadero entusiasmo. A todos los niveles de la enseñanza y de la investigación la España «europea» se ha vuelto una realidad de curiosidad, interés y simpatía. Si hoy en día los alumnos de 14 ó 15 años escogen el español como tercer idioma, ya no es (como fue el caso hace más o menos 25 años) por simpatía con los movimientos democráticos o de liberación en Hispanoamérica, sino por la nueva realidad española. El siglo XX en su totalidad representa el $44 \%$ de las menciones, y la época postfranquista ocupa casi el mismo lugar que la época anterior. En las áreas de investigación nombradas por los mismos departamentos, que se refieren al siglo XX, aparecen aspectos de la cultura española ya no estrictamente literarios, al menos si nos limitamos a una definición tradicional de lo que es «literatura». Literatura popular, cine español, los nuevos medios de comunicación en sus aspectos lingüísticos y artísticos entran en los estudios una vez centrados en una definición muy estrecha de la literatura. Esta tendencia, que por supuesto existe igualmente en otras disciplinas filológicas, coincide con la creciente importancia de nuevos medios culturales en las sociedades europeas actuales. Y también es verdad que la cultura popular española (la novela po- 
licíaca p.ej.) y el cine español ofrecen una multitud de calidades que merecen el interés de los investigadores.

La España contemporánea de la época posterior a la dictadura está igualmente en el centro de muchos estudios de politólogos, historiadores y sociólogos. Como ejemplo particularmente representativo se puede pensar en los muchos libros de Walther L. Bernecker, que publicó con numerosos colaboradores diccionarios sobre la España de hoy, visiones panorámicas del desarrollo de los últimos 25 años, estudios sobre las relaciones hispano-alemanas, etc.

Este breve recorrido a través de la lingüística y de las épocas literarias no representa, claro está, la totalidad de las investigaciones hispanistas. Antes de presentar nuevas carreras universitarias quisiera añadir algunos puntos más sobre la investigación que pueden ser de interés. Generalmente se puede decir que en muchos estudios que salen de facultades alemanas, suizas o austríacas (no sólo de la hispanística) la parte dedicada a la teoría de la literatura (o historia) o a la metodología es bastante grande. Sin embargo, no hay discusiones metodológicas que se refieran específicamente a temas hispánicos. Otra tendencia visible desde hace al menos 10 años es la publicación de visiones históricas de la literatura española, en otras palabras: hoy en día tenemos 5 ó 6 historias de la literatura española (desde los comienzos hasta el presente) en lengua alemana, ${ }^{16}$ una tendencia que se puede explicar por un lado con el gran número de estudiantes que necesitan ese tipo de libro, por otra parte con lo que llamé una fase de "saber cumulativo» que se observa también en otros detalles de la investigación actual. Efectivamente, se puede tener la impresión de que las transformaciones del mundo universitario (crisis financiera, búsqueda de una formación académica más adecuada al mundo de hoy, reflexión sobre el papel público de las universidades, etc.) lleve disciplinas como la hispanística (en general se puede decir que sobre todo la totalidad de las ciencias humanas y sociales están en crisis) a una autorreflexión profunda, que no se expresa unicamente en proyectos cumulativos, sino también en investigaciones alrededor de la historia de la propia disciplina (se vean p.ej. los proyectos mencionados en la nota 9). En los últimos años se han publicado numerosos trabajos sobre la romanística durante el tercer Reich, pero también sobre los orígenes en el siglo XIX. Esta búsqueda de las raíces y la reflexión sobre el papel político, más o menos comprometido con corrientes socio-políticas, de una disciplina que se ocupa de una cultura diferente de la suya, a mi modo de ver llega justamente en un momento en que nuevas fórmulas, nuevas definiciones de lo que puede ser la filología hoy parecen no sólo necesarias psino también realizables. Autorreflexión histórica y confianza en el futuro son las dos caras de la misma medalla. 
El Hispanismo actual en los países de habla alemana

\section{Nuevas carreras universitarias}

La nueva orientación de la hispanística, que no significa en absoluto una negación de las grandes tradiciones académicas, filológicas, de la romanística, ya se hizo realidad en algunas universidades. La tradición conocía, tanto en Alemania como en Austria y Suiza, una formación filológica con una parte dedicada al aprendizaje del idioma, otra a la lingüística y la tercera a la literatura. Esa formación llevaba a una carrera como profesor de instituto, o bien al Magister Artium, que dejaba a los licenciados sin orientación clara para el mercado del trabajo, de manera que muchos tardaron bastante tiempo antes de encontrar una ocupación que correspondía a su formación. La falta de adaptación del Magister Artium llevó a algunas universidades (parece que las más pequeñas y jóvenes veían menos inconveniente en dicha nueva orientación que las "grandes» y tradicionalistas) a crear nuevas carreras orientadas desde el principio al mercado del trabajo. La idea básica es la de mantener el núcleo de la formación filológica, añadiendo una parte de estudio de la realidad socio-política de la cultura estudiada así como competencia en una ciencia "pragmática», en general de economía y/o gestión, pero también en otros casos de jurisprudencia. En las universidades donde se establecieron esas carreras ya hay resultados que parecen muy positivos: en Gießen, Passau, Mannheim, Berlín, Kassel y pocas universidades más los jóvenes que salen de dichas carreras interdisciplinarias tienen mucho más éxito en el mercado del trabajo que sus compañeros de las carreras tradicionales. La última novedad muy discutida en Alemania (menos en Austria y Suiza) es la posible introducción de carreras de «corta duración», el Bachelor of Arts (B.A.), que lleva a un diploma universitario después de tres años y que permitiría a los mejores seguir con dos años más hasta un Master of Arts, una versión actualizada y modernizada del Magister Artium tradicional. Pero repito, esta última tendencia es muy reciente y hay pocas universidades que se lanzaron a esta aventura: nadie puede garantizar el éxito del B.A., pero sí merece la pena intentarlo.

\section{Posibles perspectivas futuras}

Queda claro que la situación actual es compleja en el sentido de que el auge del hispanismo coincide con una profunda reestructuración de la disciplina. La fuerza del hispanismo en los países de lengua alemana está sin duda en la continuidad del interés por la cultura española: la coyuntura 
parece estable cuando se observa el gran número de alumnos de entre 12 y 15 años que escogen el castellano. Pero también me permito señalar una debilidad estructural de nuestro sistema: no hay (o casi) verdaderos centros de hispanismo. En casi la totalidad de las universidades la investigación y enseñanza depende de individuos: catedráticos que enseñan español y francés y/o italiano. Cada una de las universidades puede tener éxito en sus esfuerzos a favor del hispanismo, pero apenas alguien cambia de plaza, las estructuras débiles ponen en peligro la continuidad.

También existe el problema de la lengua, problema muy discutido desde hace años: muchos de los trabajos publicados por hispanistas alemanes (también es el caso de Austria pero no de Suiza donde es costumbre enseñar y publicar casi todo en castellano) están escritos en alemán, lengua que en nuestros días está poco difundida en los ambientes universitarios internacionales. Es verdad que hay una tendencia en los últimos años hacia publicaciones en castellano, pero el hispanismo sigue siendo una disciplina bastante autorreferencial en el sentido de que para una carrera universitaria no cuenta la publicación en el extranjero (en revistas españolas por ejemplo), el criterio principal para ganar oposiciones es un criterio exclusivamente alemán. Esta problemática quizá exista también en otros países, y, si así es, sería tiempo de romper esa especie de «nacionalismo» siglo XIX. Algunas deficiencias se notan igualmente en la formación de los postgraduados. El hispanismo internacional podría buscar y crear posibilidades para una mayor cooperación en los estudios postgraduados, sea a nivel europeo o simplemente internacional. Ésta sí que es una perspectiva para el siglo XXI.

\section{Notas}

1 En el siguiente artículo intentaré contemplar la realidad en Alemania, Austria y Suiza ignorando las evidentes diferencias entre dichos países. Hay que subrayar, sin embargo, lo que dijo Wido Hempel en su reciente artículo sobre los estudios sobre el teatro español del siglo XVII en los países de habla alemana (Rassegna iberistica 67/1999, p. 1735): el concepto mismo de hispanismos nacionales es cuestionable, "pues lo que en realidad cuenta es el hispanismo (en singular y sin adjetivos)» (p. 25).

2 El número 467-468 del tomo CXIX (nov.-dic. 1984) de ARBOR comprende una serie de contribuciones sobre el hispanismo de lengua alemana, algunas sobre cuestiones históricas y otras sobre el hispanismo actual.

3 Desde hace más de 20 años se publica la bibliografía del hispanismo en lengua alemana (Bibliographie der deutschsprachigen Hispanistik, ed. por Christoph Strosetzki, Universidad de Muenster), en forma impresa (editorial Vervuert) y ahora disponible en la red (dirección internet: «www.uni-muenster.de/Romanistik/hispan/biblio/gliederung.htm»); para 


\section{El Hispanismo actual en los países de habla alemana}

una orientación general véase el volumen Hispanistik an den Hochschulen in Deutschland, Österreich und der deutschsprachigen Schweiz, ed. por Christoph Strosetzki (a cargo de la Asociación alemana de hispanistas), Vervuert 1998 (datos y direcciones de todos los departamentos de hispanística en Alemania, Suiza y Austria).

Para los que utilizan la red: las universidades alemanas se encuentran fácilmente poniendo "www.uni-nombre de la ciudad.de», en Austria y Suiza es menos cómodo ya que hay que poner abreviaturas tal como para Salzburg "www.sbg.ac.at" = salzburg, academia, austria.

4 Véase al respecto el artículo de Karl Kohut: "La hispanística alemana entre literatura comparada y literatura nacional", en ARBOR (467-468 del tomo CXIX, nov.-dic. 1984) p.39-46.

5 Deutscher Hispanistenverband (DHV, actual presidente: Dieter Ingenschay, Humboldt Universität zu Berlin, correo electrónico: «dieter.ingenschay@rz.huberlin.de»). También existe una Asociación de los profesores de instituto (Deutscher Spanischlehrerverband DSV, homepage "www.uni-muenster.de/Romanistik/dsv/»).

6 Zeitschrift für Katalanistik. Sobre la catalanística en Alemania véase el artículo de Josep María Navarro de Adriaensens: «Lengua y cultura catalanas en Alemania», en ARBOR (467-468 del tomo CXIX, nov.-dic. 1984) p.47-58.

7 Ante todo hay que mencionar el prestigioso Ibero-Amerikanisches Institut en Berlín (Instituto Ibero-Americano. Fundación Patrimonio Cultural Prusiano; "www.iai.spk-berlin.de»), un centro interdisciplinario y una de las más importantes y completas bibliotecas para Iberoamérica, Portugal y España.

8 Me refiero a los datos publicados por la DFG en la red relativos al año 1998. Actualmente la DFG está construyendo un banco de datos que permitirá tener una visión de conjunto actualizada de los proyectos de investigación subvencionados así como una búsqueda temática.

9 Lexikon der romanistischen Linguistik (Göttingen/Bonn); Retrospektive Bibliographie zur Geschichte der spanischen Sprachwissenschaft (Trier).

10 Por supuesto, lo digo para evitar malentendidos, hay una gran cantidad de tesis de doctorado sobre temas hispánicos; véanse los repertorios José Rodríguez Richart: «'Habilitationsschriften' tesis de doctorado realizadas en las Universidades de Austria, de la República Democrática Alemana y de la República Federal de Alemania sobre temas de lengua y literatura española y portuguesa (1945-1974), en: Iberoromania 3/1975; André Herrmann/Gustav Siebenmann: «Verzeichnis der Spanien, Portugal und Lateinamerika betreffenden Schweizer Hochschulschriften aus dem Gebiet der Geistes- und Sozialwissenschaften (1897-1977), en Iberoromania 8/1978, y para una visión más actual las listas publicadas anualmente en el Romanistisches Jahrbuch. Entre 1988 y 1997 se realizaron más de 120 tesis de tema hispánico.

11 Habrá quien no comparta esta decisión. Sin embargo, mirando otras publicaciones sobre hispanismo en el mundo (una serie de artículos publicados en ARBOR en los últimos años), creo que una diferenciación entre hispanismo peninsular e hispanismo americano se hace cada vez más usual y, por lo tanto, necesaria.

12 Sobre dichas tradiciones informa Hans-Martin Gauger: «Los orígenes de la lingüística hispánica», en ARBOR (467-468 del tomo CXIX, nov.-dic. 1984) p.59-68.

13 Art. citado en la nota 1.

14 Véase el artículo de Hans-Joachim Lope: «El siglo XVIII y el hispanismo alemán: avances y contribuciones de los últimos veinte años», en ARBOR (467-468 del tomo CXIX, nov.-dic. 1984) p.95-104. 
15 Este hecho se refleja también en el número casi inexistente de miembros alemanes en la Sociedad de Literatura Española del Siglo XIX.

16 Hay dos reseñas recientes que presentan las historias más interesantes: Gustav Siebenmann: «Konjunktur spanischer Literaturgeschichten in Deutschland", en Iberoromania 41, 1995, p.117-136; José Manuel López de Abiada: «Ein Boom spanischer Literatrurgeschichten in Deutschland», en Tranvía 51, 12/1998, p.55-57. 